\title{
Analisis Dinamik Model Penyebaran Aflatoksin pada Manusia dan Hewan
}

\author{
Wuryansari Muharini Kusumawinahyu, Yuni Ayu Anita \\ Jurusan Matematika Universitas Brawijaya \\ Jl. Veteran Malang 65145 \\ wmuharini@ub.ac.id
}

\begin{abstract}
Abstrak
Pada penelitian ini dibahas suatu model yang menggambarkan perubahan konsentrasi aflatoksin pada tanaman, hewan, dan manusia, yang menyebar melalui makanan dan pakan ternak yang berasal dari tanaman. Pada model yang berupa sistem autonomus ini dilakukan analisis dinamik yang meliputi penentuan titik kesetimbangan, syarat eksistensi titik kesetimbangan, angka reproduksi dasar, dan analisis kestabilan lokal titik kesetimbangan. Hasil analisis dinamik menunjukkan bahwa model memiliki empat titik kesetimbangan dan dua angka reproduksi dasar. Tiga titik kesetimbangan eksis dengan syarat tertentu. Kestabilan titik kesetimbangan aksial bergantung pada angka reproduksi dasar, sedangkan titik kesetimbangan interior selalu stabil asimtotik lokal bila ia eksis. Hasil simulasi numerik yang dilakukan mendukung hasil analisis dinamik.

Kata kunci: aflatoksin, makanan, pakan ternak, angka reproduksi dasar, kestabilan lokal

Abstract

This research discusses a model that illustrates the changes of the concentration of aflatoxins in plants, animals and humans, which spread through food and animal feed consumption. Dynamical analysis on the model is performed by finding the equilibrium point, the existence condition of the equilibrium point, the basic reproduction number, and by analizing the local stability of equilibrium point. The results of the dynamical analysis show that there are four equilibrium points and two basic reproduction numbers. The three equilibrium points exist under some certain conditions. The stability of the axial equilibrium points depend on the basic reproduction numbers, while the interior equilibrium point is always local asymptotically stable when it exists. The performed numerical simulation supports the results of dynamical analysis.

Keywords: aflatoxin, foods, feeds, basic reproduction number, local stability.
\end{abstract}

\section{Pendahuluan}

Makanan merupakan kebutuhan pokok manusia yang mengandung berbagai sumber nutrisi. Namun demikian, pada kenyataannya manusia dapat terserang penyakit yang diakibatkan oleh zat beracun yang terdapat pada makanan. Ada dua jenis zat racun yang terkandung dalam

2000 Mathematics Subject Classification: 37N25.

Submitted: 2020-05-22, Revised: 2020-06-19, Accepted: 2020-07-03 Key words and Phrases: aflatoksin, makanan, pakan ternak, angka reproduksi dasar, kestabilan lokal. 
makanan, yaitu zat beracun alami dan zat racun buatan. Mikotoksin merupakan zat beracun alami yang berasal dari fungi dan sering ditemukan dalam makanan. Aflatoksin merupakan salah satu jenis mikotoksin yang berbahaya (Kifer, dkk., [5]). Kata afla pada aflatoksin merupakan kependekan dari Aspergiluus flavus, sebab aflatoksin dihasilkan oleh segolongan fungi dari genus Aspergillus, terutama A. flavus dan A. parasiticus yang berasosiasi dengan produkproduk biji-bijian berminyak atau berkarbohidrat tinggi. Kandungan aflatoksin ditemukan pada biji kacang-kacangan (kacang tanah, kedelai, pistacio, atau bunga matahari), rempahrempah (seperti ketumbar, jahe, lada, serta kunyit), dan serealia seperti gandum, padi, sorgum, dan jagung (Astawan, [1]). Aflatoksin adalah salah satu jenis zat racun yang umum dan paling berbahaya dalam makanan dan pakan karena penyebarannya merata. Menurut European Commission [8] dalam Kademi, dkk. [3], tingkat aflatoksin maksimum yang direkomendasikan dalam makanan manusia adalah empat ppb (part per billion).

Meningkatnya peluang aflatoksin terkandung dalam makanan dan pakan ternak mendorong dilakukannya berbagai penelitian untuk mempelajari fenomena yang terkait dengan aflatoksin dengan memanfaatkan model matematika. Sebagai contoh, Molina dan Giannuzzi [7] membahas pemodelan produksi aflatoksin oleh Aspergillus parasiticus dalam media padat dengan menggunakan analisis statistika. Selanjutnya, Marin, dkk. [6] menggunakan model pertumbuhan, model akumulasi aflatoksin, dan model probalitas untuk mengetahui model pertumbuhan Aspergillus flavus dan produksi aflatoksin pada kacang pistachio. Battilani, dkk. [2] membahas AFLA-meize, model mekanistik untuk infeksi Aspergillus flavus, dan kontaminasi aflatoksin B1 pada jagung menggunakan metode prediksi prototipe. Pada tahun 2017, Kademi, dkk. [3] mengusulkan suatu model matematika yang menggambarkan laju perpindahan kandungan aflatoksin di antara tumbuhan, populasi manusia, dan populasi hewan. Model yang dikonstruksi berupa sistem dinamik yang mengadopsi model penyebaran penyakit tipe SIR (Susceptible-Infected-Removed). Model tersebut memandang empat variabel yang menyatakan konsentrasi aflatoksin pada tanaman, manusia, hewan, dan konsentrasi aflatoksin yang hilang dari tanaman, manusia, dan hewan. Analisis dinamik yang mereka lakukan pada model meliputi penentuan titik kesetimbangan dan syarat eksistensinya, penentuan angka reproduksi dasar, dan analisis kestabilan lokal. Pada penelitian tersebut diperoleh empat titik kesetimbangan dan dua angka reproduksi dasar pada model. Eksistensi tiga titik kesetimbangan bergantung pada angka reproduksi dasar dan keempat titik kesetimbangan stabil asimtotik lokal jika memenuhi syarat tertentu. Selanjutnya, pada tahun 2019, Kademi, dkk. [4] menyelidiki mitigasi risiko adanya aflatoksin pada makanan, dengan memandang model matematika yang merepresentasikan interaksi antara aflatoksin dan probiotik. Dalam penelitiannya, Kademi, dkk. [4] menggunakan laju interaksi Michaelis Menten untuk menggambarkan adanya fenomena saturasi dalam interaksi antara aflatoksin dengan probiotik. Pada tahun 2020, Kifer, dkk. [5] melakukan review terhadap beberapa model regresi yang menggambarkan efek yang dihasilkan oleh kombinasi beberapa mikotoksin.

Dalam penelitian ini kami mengkaji kembali model yang diusulkan oleh Kademi, dkk. [3], dengan tujuan untuk melakukan analisis dinamik dan membandingkan hasilnya dengan hasil yang diperoleh Kademi, dkk. [3]. Berdasarkan analisis yang kami lakukan, diperoleh empat titik kesetimbangan yang sama dengan yang diperoleh Kademi, dkk. [3]. Namun, pada titik kesetimbangan ke tiga diperoleh syarat eksistensi yang berbeda. Selain itu, berbeda dari hasil penelitian Kademi, dkk. [3], dapat dibuktikan bahwa titik kesetimbangan interior bersifat stabil asimtotik lokal bila titik tersebut eksis, sedangkan pada Kademi, dkk. [3] titik tersebut bersifat tidak stabil bila titik tersebut eksis. Pada bagian akhir penelitian disajikan hasil simulasi numerik untuk mendukung hasil analisis. Perlu dicatat bahwa terdapat dua simulasi numerik pada Kademi, dkk. [3] yang tidak sesuai dengan hasil analisis dan situasi sesungguhnya, sebab simulasi yang dilakukan Kademi, dkk. [3] menghasilkan konsentrasi aflatoksin pada hewan yang bernilai negatif. 


\section{Model Matematika}

Model matematika penyebaran aflatoksin pada manusia dan hewan yang dikembangkan oleh Kademi, dkk. [3] dikonstruksi dengan mengasumsikan bahwa aflatoksin berasal dari tanaman, laju pertambahan konsentrasi aflatoksin pada tanaman konstan, dan konsentrasi aflatoksin pada manusia lebih tinggi daripada konsentrasinya pada hewan, karena pada umumnya manusia mengkonsumsi produk makanan yang berasal dari tumbuhan dan hewan. Model tersebut terdiri dari empat variabel, yaitu konsentrasi aflatoksin pada tanaman $(P(t))$, konsentrasi aflatoksin pada hewan $(A(t))$, konsentrasi aflatoksin pada manusia $(H(t))$, dan konsentrasi aflatoksin yang hilang dari hewan dan manusia $(R(t))$.

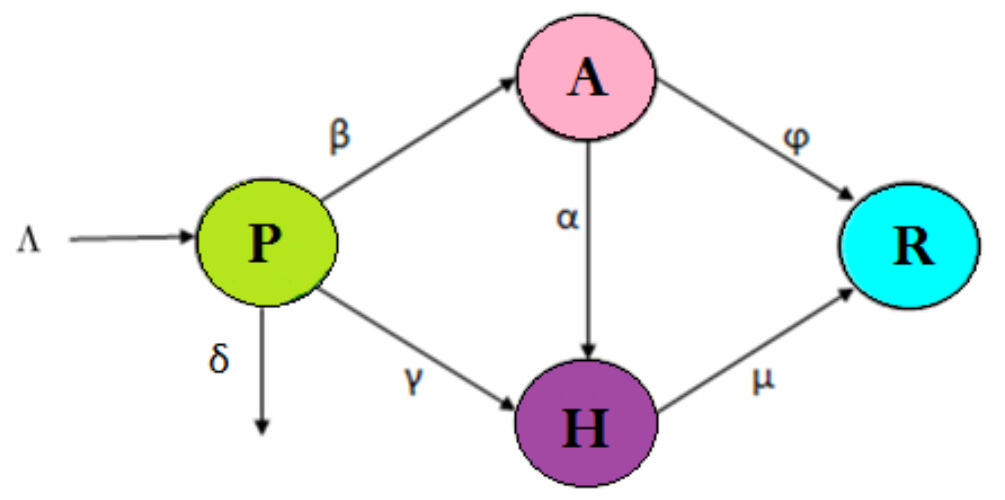

GAmbar 1. Diagram kompartemen model penyebaran aflatoksin pada makanan dan pakan (Kademi, dkk., [3])

Dengan menerjemahkan diagram kompartemen pada Gambar 1, yang menggambarkan perpindahan aflatoksin di antara tanaman, hewan, dan manusia, Kademi, dkk. [3] merumuskan model matematika berikut.

$$
\begin{aligned}
& \frac{d P}{d t}=\Lambda-\beta P A-\gamma P H-\delta P \\
& \frac{d A}{d t}=\beta P A-\varphi A-\alpha A H \\
& \frac{d H}{d t}=\gamma P H-\mu H+\alpha A H \\
& \frac{d R}{d t}=\varphi A+\mu H,
\end{aligned}
$$

dengan parameter-parameter $\Lambda, \beta, \gamma, \delta, \alpha, \varphi$, dan $\mu$ berturut-turut menyatakan laju bertambahnya aflatoksin pada tanaman, laju perpindahan aflatoksin dari tanaman ke hewan, laju perpindahan aflatoksin dari tanaman ke manusia, laju hilangnya aflatoksin pada tanaman, laju perpindahan aflatoksin dari hewan ke manusia, laju hilangnya aflatoksin pada hewan, dan laju hilangnya aflatoksin pada manusia. Karena tiga persamaan pertama pada persamaan (1) tidak memuat variabel $R$ maka pembahasan selanjutnya hanya menggunakan tiga persamaan pertama, yaitu 


$$
\begin{aligned}
\frac{d P}{d t} & =\Lambda-\beta P A-\gamma P H-\delta P \\
\frac{d A}{d t} & =\beta P A-\varphi A-\alpha A H \\
\frac{d H}{d t} & =\gamma P H-\mu H+\alpha A H .
\end{aligned}
$$

\section{Analisis Dinamik}

3.1. Titik Kesetimbangan dan Syarat Eksistensi. Seperti pada penelitian yang dilakukan oleh Kademi, dkk. [3], pada penelitian ini juga diperoleh empat titik kesetimbangan, yaitu $E_{0}=\left(\frac{\Lambda}{\delta}, 0,0\right), E_{1}=\left(\frac{\mu}{\gamma}, 0, \frac{\Lambda \gamma-\delta \mu}{\mu \gamma}\right), E_{2}=\left(\frac{\varphi}{\beta}, \frac{\Lambda \beta-\delta \varphi}{\varphi \beta}, 0\right)$, dan $E_{3}=\left(P^{*}, A^{*}, H^{*}\right)$, dengan

$$
\begin{aligned}
P^{*} & =\frac{\Lambda \alpha}{\beta \mu-\gamma \varphi+\alpha \delta}, \\
A^{*} & =\frac{\mu(\beta \mu-\gamma \varphi+\alpha \delta)-\Lambda \gamma \alpha}{\alpha(\beta \mu-\gamma \varphi+\alpha \delta)}, \\
H^{*} & =\frac{\Lambda \beta \alpha-\varphi(\beta \mu-\gamma \varphi+\alpha \delta)}{\alpha(\beta \mu-\gamma \varphi+\alpha \delta)} .
\end{aligned}
$$

Titik $E_{1}$ eksis jika $R_{02}=\frac{\Lambda \gamma}{\delta \mu}>1$, yang dapat diartikan bahwa manusia akan terkontaminasi aflatoksin bila $R_{02}>1$. Titik $E_{2}$ eksis jika $R_{01}=\frac{\Lambda \beta}{\delta \varphi}>1$. Hal ini dapat diartikan bahwa hewan akan terkontaminasi aflatoksin bila $R_{01}>1$. Syarat eksistensi untuk titik $E_{3}$ adalah $\beta \mu-\gamma \varphi+\alpha \delta>0, \beta \mu-\gamma \varphi+\alpha \delta<\frac{\Lambda \beta \alpha}{\varphi}$, dan $\beta \mu-\gamma \varphi+\alpha \delta>\frac{\Lambda \gamma \alpha}{\mu}$. Ketiga syarat tersebut dapat digabung menjadi $\frac{\Lambda \gamma \alpha}{\mu}<\beta \mu-\gamma \varphi+\alpha \delta<\frac{\Lambda \beta \alpha}{\varphi}$. Bila setiap ruas dikalikan dengan $\frac{1}{\alpha \delta}$ maka diperoleh

$$
\frac{\Lambda \gamma}{\delta \mu}<\frac{\beta \mu-\gamma \varphi+\alpha \delta}{\alpha \delta}<\frac{\Lambda \beta}{\delta \varphi}
$$

Jika dimisalkan $T=\frac{\beta \mu-\gamma \varphi+\alpha \delta}{\alpha \delta}$ maka syarat eksistensi titik kesetimbangan $E_{3}$ adalah $R_{02}<T<R_{01}$. Syarat eksistensi titik $E_{3}$ pada penelitian ini berbeda dari syarat eksistensi yang diperoleh Kademi, dkk. [3], yaitu $R_{02}=R_{01}$. Teorema berikut memperlihatkan bahwa syarat eksistensi $E_{3}$ pada Kademi, dkk., [3] mengakibatkan $E_{3}=E_{0}$, sehingga dapat dikatakan $E_{3}$ tidak eksis.

Teorema 3.1. Jika $R_{02}=R_{01} \operatorname{maka} E_{3}=E_{0}$.

Bukti: Jika $R_{02}=R_{01}$ maka $\frac{\Lambda \gamma}{\delta \mu}=\frac{\Lambda \beta}{\delta \varphi}$. Akibatnya $\beta \mu=\gamma \varphi$. Jika $\beta \mu=\gamma \varphi$ disubstitusikan ke titik kesetimbangan $E_{3}$ maka diperoleh $P^{*}=\frac{\Lambda}{\delta}, A^{*}=\frac{\mu \delta-\Lambda \gamma}{\alpha \delta}$, dan $H^{*}=\frac{\beta \Lambda-\varphi \delta}{\alpha \delta}$. Substitusi titik kesetimbangan $E_{3}=\left(P^{*}, A^{*}, H^{*}\right)$ ke persamaan (2) menghasilkan

$$
\Lambda-\beta P^{*} A^{*}-\gamma P^{*} H^{*}-\delta P^{*}=0 .
$$

Karena $P^{*}=\frac{\Lambda}{\delta}$ maka

$$
-P^{*}\left(\beta A^{*}+\gamma H^{*}\right)=0
$$


yang mengakibatkan

$$
A^{*}=-\frac{\gamma H^{*}}{\beta} \leq 0 \text { atau } H^{*}=-\frac{\beta H^{*}}{\gamma} \leq 0
$$

Mustahil $A^{*}<0$ atau $H^{*}<0$ sehingga $A^{*}=H^{*}=0$. Akibatnya $E_{3}=\left(\frac{\Lambda}{\delta}, 0,0\right)=E_{0}$

3.2. Kestabilan Lokal Titik Kesetimbangan. Sifat kestabilan lokal titik kesetimbangan model ditentukan dengan melakukan linearisasi sistem otonomus nonlinear (2) di sekitar titik kesetimbangan dan diperoleh matriks Jacobi

$$
J=\left[\begin{array}{ccc}
-\beta A-\gamma H-\delta & -\beta P & -\gamma P \\
\beta A & \beta P-\varphi-\alpha H & -\alpha A \\
\gamma H & \alpha H & \gamma P-\mu+\alpha A
\end{array}\right] .
$$

Seperti hasil yang diperoleh pada penelitian Kademi, dkk. [3], titik kesetimbangan $E_{0}$ bersifat stabil asimtotik lokal jika $R_{02}<1$ dan $R_{01}<1$, titik kesetimbangan $E_{1}$ bersifat stabil asimtotik lokal jika $R_{01}<R_{02}$, dan titik kesetimbangan $E_{2}$ bersifat stabil asimtotik lokal jika $R_{02}<R_{01}$. Menurut teorema 4 pada Kademi, dkk. [3], titik kesetimbangan $E_{3}$ bersifat stabil asimtotik lokal bila $R_{01}>1+R_{02}$. Hal ini bertentangan dengan syarat eksistensi titik kesetimbangan $E_{3}$ pada Kademi, dkk. [3], yaitu $R_{01}=R_{02}$, sehingga titik $E_{3}$ selalu bersifat tidak stabil bila syarat eksistensinya dipenuhi. Hasil yang berbeda kami peroleh pada analisis kestabilan lokal titik kesetimbangan $E_{3}$, seperti disajikan pada teorema 3.2.

Teorema 3.2. Jika titik kesetimbangan $E_{3}$ eksis, maka titik $E_{3}$ bersifat stabil asimtotik lokal

Bukti: Matriks Jacobi pada titik kesetimbangan $E_{3}=\left(P^{*}, A^{*}, H^{*}\right)$ adalah

$$
J\left(E_{3}\right)=\left[\begin{array}{ccc}
a_{11} & -\beta P^{*} & -\gamma P^{*} \\
\beta A^{*} & 0 & -\alpha A^{*} \\
\gamma H^{*} & \alpha H^{*} & 0
\end{array}\right],
$$

dengan $a_{11}=-\beta A^{*}-\gamma H^{*}-\delta$.

Persamaan karakteristik matriks Jacobi $J\left(E_{3}\right)$ adalah

$$
\lambda^{3}+B_{1} \lambda^{2}+B_{2} \lambda+B_{3}=0,
$$

dengan $B_{1}=-a_{11}, B_{2}=\alpha^{2} H^{*} A^{*}+\beta^{2} A^{*} P^{*}+\gamma^{2} P^{*} H^{*}$, dan $B_{3}=-\alpha^{2} H^{*} A^{*} a_{11}$. Jelas bahwa $B_{1}>0$ dan $B_{3}>0$, sedangkan

$$
\begin{aligned}
B_{1} B_{2}-B_{3} & =-a_{11}\left(\alpha^{2} H^{*} A^{*}+\beta^{2} A^{*} P^{*}+\gamma^{2} P^{*} H^{*}\right)+\alpha^{2} H^{*} A^{*} a_{11} \\
& =-a_{11}\left(\beta^{2} A^{*} P^{*}+\gamma^{2} P^{*} H^{*}\right)>0 .
\end{aligned}
$$

Berdasarkan kriteria Routh-Hurwitz maka titik kesetimbangan $E_{3}$ bersifat stabil asimtotik lokal.

Syarat eksistensi dan jenis kestabilan titik kesetimbangan sistem persamaan (2) dirangkum pada Tabel 1. Terlihat bahwa ketidakstabilan titik kesetimbangan $E_{0}$ mengakibatkan eksistensi titik kesetimbangan $E_{1}$ atau $E_{2}$, sedangkan ketidakstabilan titik kesetimbangan $E_{1}$ dapat menyebabkan titik $E_{3}$ eksis. Jadi eksistensi titik $E_{1}, E_{2}, E_{3}$ dan sifat kestabilan titik $E_{0}, E_{1}$, dan $E_{3}$ ditentukan oleh posisi angka reproduksi dasar $R_{02}$ dan $R_{01}$ pada garis bilangan real. Perhatikan bahwa $R_{02}<R_{01}$ mengakibatkan $\gamma \varphi<\beta \mu$. Hal ini menyebabkan $T=1+\frac{\beta \mu-\gamma \varphi}{\alpha \delta}>1$. Dengan demikian, bila $R_{02}<1$ dan $R_{01}<1$ maka hanya titik kesetimbangan $E_{0}$ yang eksis dan bersifat stabil asimtotik lokal. Hal ini dapat diartikan bahwa dalam jangka waktu yang lama aflatoksin hanya akan terdapat pada tanaman, sedangkan aflatoksin pada hewan dan manusia akan habis. 
46 Kusumawinahyu dkk, JMI Vol 16(1) April 2020 pp. 41-yy,doi:10.24198/jmi.v16.n1.27492.41-51

TABEL 1. Titik kesetimbangan, syarat eksistensi, dan kestabilan model (2)

\begin{tabular}{|c|c|c|c|}
\hline Titik kesetimbangan & Syarat eksistensi & Jenis kestabilan & Syarat kestabilan \\
\hline$E_{0}=\left(\frac{\Lambda}{\delta}, 0,0\right)$ & - & Stabil Asimtotik lokal & $R_{02}<1$ dan $R_{01}<1$ \\
\hline$E_{1}=\left(\frac{\mu}{\gamma}, 0, \frac{\Lambda \gamma-\delta \mu}{\mu \gamma}\right)$ & $R_{02}>1$ & Stabil Asimtotik lokal & $R_{01}<R_{02}$ \\
\hline$E_{2}=\left(\frac{\varphi}{\beta}, \frac{\Lambda \beta-\delta \varphi}{\varphi \beta}, 0\right)$ & $R_{01}>1$ & Stabil Asimtotik lokal & $R_{02}<R_{01}$ \\
\hline$E_{3}=\left(P^{*}, A^{*}, H^{*}\right)$ & $R_{02}<T<R_{01}$ & Stabil Asimtotik lokal & - \\
\hline
\end{tabular}

\section{Simulasi NumeriK}

Untuk mengilustrasikan hasil analisis yang telah dilakukan pada bagian 3 dilakukan simulasi numerik yang mengacu kepada Tabel 1, yaitu dengan memandang lima kasus berikut.

(1) Kasus $R_{01}<1, R_{02}<1$

(2) Kasus $R_{01}>1, R_{02}<1$ dan $R_{02}<R_{01}<T$

(3) Kasus $R_{01}<1, R_{02}>1$

(4) Kasus $R_{01}>1, R_{02}>1$, dan $T<R_{01}<R_{02}$

(5) Kasus $R_{01}>1, R_{02}>1$, dan $R_{02}<T<R_{01}$

Nilai-nilai parameter yang digunakan dalam simulasi ini adalah $\alpha=\delta=\mu=0.1, \Lambda=0.8$, sedangkan parameter-parameter yang lain diberikan pada Tabel 2. Nilai-nilai parameter tersebut dipilih agar memenuhi kondisi $R_{01}, R_{02}$, dan $T$ pada kelima simulasi yang dilakukan. Akronim SAL pada Tabel 2 bermakna Stabil Asimtotik Lokal.

TABEL 2. Parameter simulasi numerik

\begin{tabular}{|l|l|l|l|l|l|l|l|}
\hline Kasus & $\beta$ & $\gamma$ & $\phi$ & $R_{01}$ & $R_{02}$ & $T$ & Keterangan \\
\hline$R_{01}<1, R_{02}<1$ & 0.003 & 0.002 & 0.08 & 0.3 & 0.16 & 1.014 & $E_{0}$ SAL \\
\hline$R_{01}>1, R_{02}<1$ & 0.01 & 0.00009 & 0.08 & 1.1 & 0.016 & 1.108 & $E_{2}$ SAL \\
\hline$R_{01}<1, R_{02}>1$ & 0.003 & 0.02 & 0.08 & 0.3 & 1.6 & 0.87 & $E_{1}$ SAL \\
\hline $\begin{array}{l}R_{01}>1, R_{02}>1, \\
T<R_{01}<R_{02}\end{array}$ & 0.003 & 0.2 & 0.008 & 3 & 16 & 0.87 & $E_{1}$ SAL \\
\hline $\begin{array}{l}R_{01}>1, R_{02}>1, \\
R_{02}<T<R_{01}\end{array}$ & 3 & 0.02 & 0.08 & 300 & 1.6 & 30.8 & $E_{2}$ dan $E_{3}$ SAL \\
\hline
\end{tabular}

Pada kasus pertama digunakan nilai parameter seperti yang digunakan oleh Kademi, dkk. [3] pada simulasi pertamanya. Berdasarkan Tabel 1, pada kasus ini hanya terdapat titik kesetimbangan $E_{0}$ dan bersifat stabil asimtotik lokal. Pada Gambar 2 diperlihatkan hasil simulasi numerik yang berupa orbit-orbit solusi di ruang $(P, A, H)$ dengan tiga nilai awal, yaitu $N A_{1}=$ $(0.7,0.3,0.5), N A_{2}=(3,0.1,1)$, dan $N A_{3}=(5,1,2)$. Hasil simulasi menunjukkan bahwa ketiga orbit tersebut konvergen ke titik kesetimbangan $E_{0}=(8,0,0)$. Hal ini menunjukkan bahwa simulasi numerik yang dilakukan sesuai dengan hasil analisis. Pengambilan nilai parameter pada kasus ini menyebabkan laju pertumbuhan aflatoksin pada tanaman relatif besar namun laju perpindahan aflatoksin dari tanaman ke hewan dan manusia relatif kecil sehingga terjadi penumpukan aflatoksin pada tanaman. selain itu, nilai parameter $\mu$ dan $\varphi$ juga relatif besar bila dibandingkan dengan $\beta$ dan $\gamma$, sehingga laju hilangnya aflatoksin pada hewan dan manusia relatif besar. Kondisi ini menyebabkan dalam jangka waktu yang lama aflatoksin pada hewan dan manusia akan habis, sehingga aflatoksin hanya akan terdapat pada tumbuhan. Pada Kademi, dkk. [3], simulasi yang dilakukan untuk kasus ini menghasilkan konsentrasi aflatoksin pada hewan yang bernilai negatif seperti disajikan pada Fig. 2 pada paper tersebut, sedangkan pada penelitian kami diperoleh konsentrasi aflatoksin yang selalu positif pada rentang waktu simulasi yang sama, yaitu $0 \leq t \leq 20$, seperti disajikan pada Gambar 3 . 


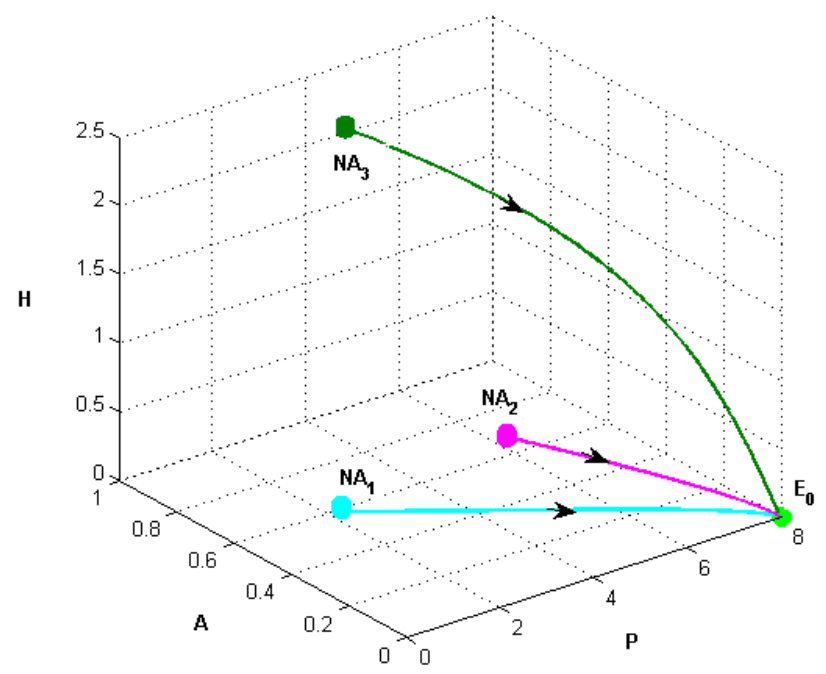

Gambar 2. Potret fase model (2) untuk kasus $R_{02}<1, R_{01}<1$. Titik $E_{0}$ stabil asimtotik lokal.

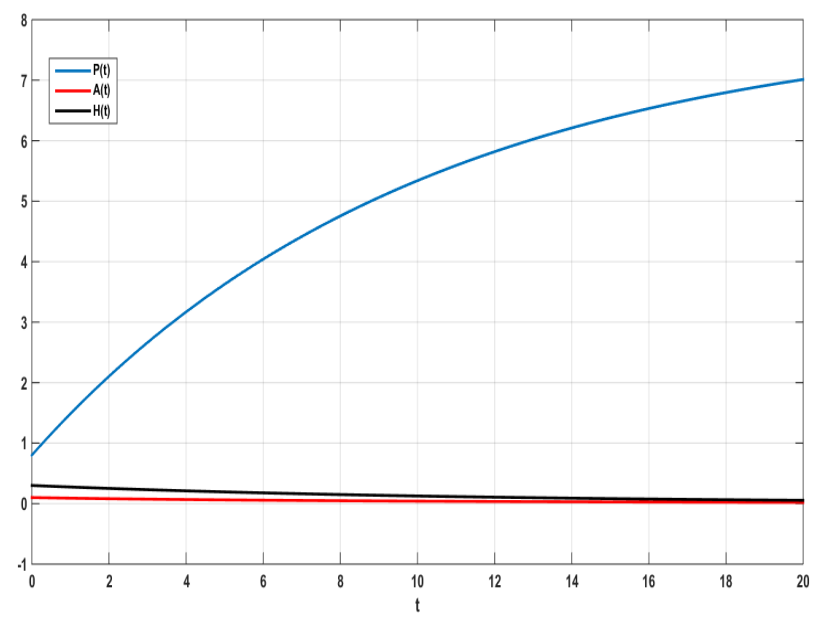

Gambar 3. Kurva solusi untuk kasus $1, R_{01}<1, R_{02}<1$. Bila selang waktu $t$ diperpanjang kurva biru $(P(t))$ akan naik terus menuju nilai 8 , sedangkan kurva merah $(A(t))$ dan hitam $(H(t))$ menuju nol.

Pada kasus ke dua diperoleh $R_{02}<R_{01}<T$, sehingga menurut Tabel 1, hanya titik $E_{0}$ dan $E_{2}$ yang eksis karena syarat eksistensi titik kesetimbangan $E_{1}$ dan $E_{3}$ tidak terpenuhi. Hasil analisis menyatakan bahwa titik $E_{2}$ stabil asimtotik lokal, sedangkan titik $E_{0}$ tak stabil pelana. Pada Gambar 4 disajikan potret fase dengan tiga nilai awal, yaitu $N A_{1}=(10,8,0), N A_{2}=(15,5,0)$, dan $N A_{3}=(20,3,0)$. Hasil simulasi menunjukkan bahwa ketiga orbit tersebut menuju ke titik kesetimbangan $E_{2}=(7.27,0.73,0)$. Hal ini menunjukkan bahwa simulasi numerik yang dilakukan sesuai dengan hasil analisis. Pada kasus ini laju pertumbuhan aflatoksin pada tanaman dan hewan relatif besar namun laju perpindahan aflatoksin dari tanaman dan hewan ke manusia relatif kecil, sehingga konsentrasi aflatoksin pada hewan 
dan tanaman tetap banyak, sedangkan aflatoksin pada manusia dalam jangka waktu yang lama akan habis.

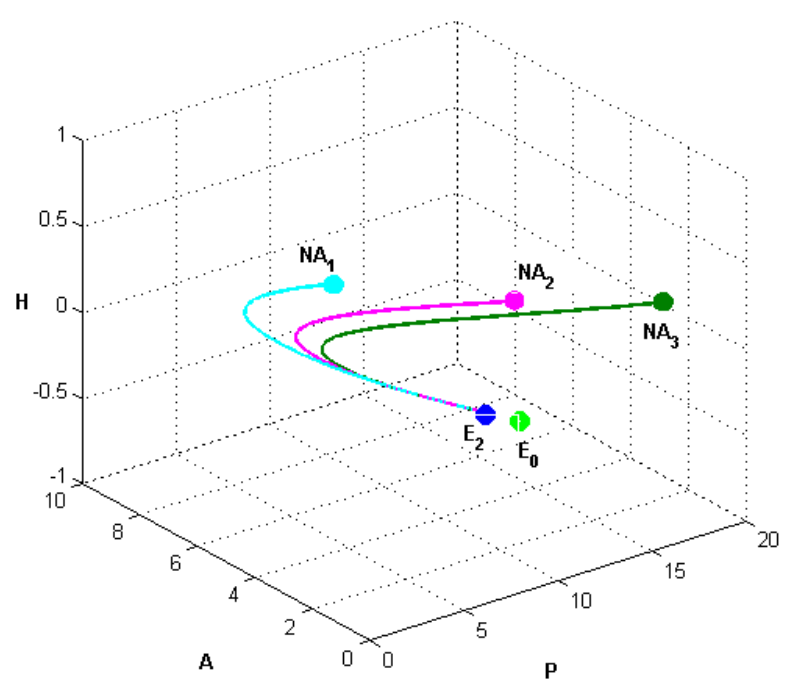

Gambar 4. Potret fase model (2) untuk kasus $R_{02}<1, R_{01}>1$, dan $R_{02}<$ $R_{01}<T$

Menurut hasil analisis pada Tabel 1, untuk kasus ke tiga hanya titik kesetimbangan $E_{0}$ dan $E_{1}$ yang eksis, karena syarat eksistensi titik kesetimbangan $E_{2}$ dan $E_{3}$ tidak terpenuhi. Pada Gambar 5 ditunjukkan potret fase dengan tiga nilai awal, yaitu $N A_{1}=(80,4,70), N A_{2}=$ $(90,10,60)$, dan $N A_{3}=(100,5,80)$. Hasil simulasi menunjukkan bahwa orbit-orbit yang berawal dari beberapa nilai awal tersebut menuju ke titik kesetimbangan $E_{1}=(5,0,3)$. Pada kasus ini laju perpindahan aflatoksin pada tanaman ke hewan relatif sedikit sedangkan laju perpindahan aflatoksin pada tanaman ke manusia relatif banyak. Kondisi ini menyebabkan bahwa dalam jangka waktu yang lama tetap ada kandungan aflatoksin pada tanaman dan manusia.

Simulasi yang dilakukan pada kasus ke empat menggunakan parameter yang sama dengan yang digunakan oleh Kademi, dkk. [3] pada simulasi mereka yang ke tiga. Pada kasus ini seluruh titik kesetimbangan eksis, kecuali titik $E_{3}$. Namun hanya titik $E_{1}$ saja yang stabil asimtotik. Hasil simulasi numerik berupa potret fase di ruang $(P, A, H)$ yang ditunjukkan pada Gambar 6 memperlihatkan bahwa orbit-orbit solusi menuju titik kesetimbangan $E_{1}=(0.5,0,7.5)$. Hal ini menunjukkan bahwa hasil simulasi numerik sesuai dengan hasil analisis. Selain itu diperlihatkan pula kurva solusi untuk $0 \leq t \leq 10$ pada Gambar 7 , yang selalu menghasilkan nilai $A(t) \geq 0$, sedangkan pada Kademi, dkk., [3] nilai $A(t)<0$ untuk $4 \leq t \leq 10$.

Pada simulasi kasus terakhir diambil nilai parameter $\beta$ yang besar agar $R_{01}>R_{02}>1$. dan $R_{02}<T<R_{01}$. Berdasarkan Tabel 1, semua titik kesetimbangan eksis, yaitu $E_{0}=$ $(8,0,0), E_{1}=(5,0,3), E_{2}=(0.027,7.97,0)$ dan $E_{3}=(0.26,0.95,7.03)$. Di antara empat titik kesetimbangan tesebut, titik $E_{2}$ dan $E_{3}$ stabil asimtotik lokal. Pada Gambar 8 ditunjukkan potret fase di ruang $(P, A, H)$ dengan enam nilai awal yang sama dengan simulasi kasus pertama dan ditambah tiga nilai awal baru, yaitu $N A_{4}=(0.1,8,0), N A_{5}=(7,0.2,0)$, dan $N A_{6}=$ $(6,2,0)$. Hasil simulasi menunjukkan bahwa orbit-orbit yang berawal dari $N A_{4}, N A_{5}$, dan $N A_{6}$ menuju titik kesetimbangan $E_{2}$ sedangkan orbit-orbit yang lain menuju titik kesetimbangan $E_{3}$. Hal ini menunjukkan bahwa kestabilan $E_{2}$ dan $E_{3}$ tidak bersifat global melainkan hanya stabil asimtotik lokal. Dengan demikian, simulasi numerik yang dilakukan mendukung hasil analisis. 


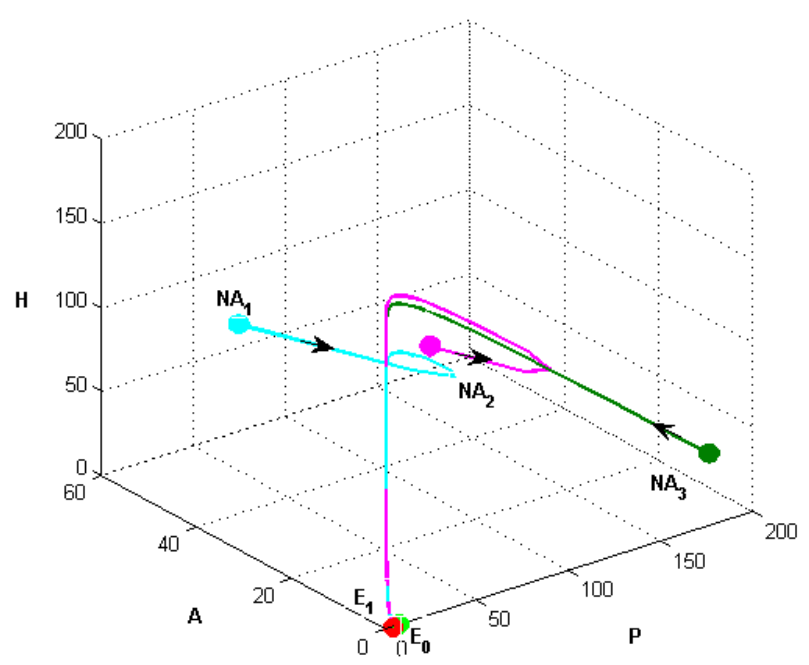

Gambar 5. Potret fase model (2) untuk kasus $R_{02}>1$ dan $R_{01}<1$

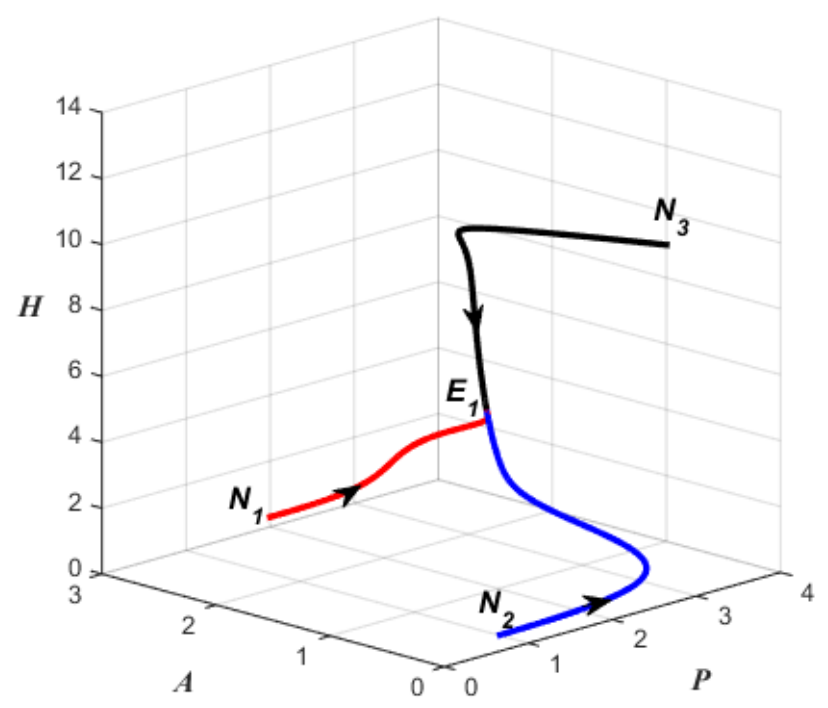

Gambar 6. Potret Fase untuk kasus $R_{01}>1, R_{02}>1, T<R 01<R_{02}$. Titik $E_{1}$ stabil asimtotik lokal

\section{Kesimpulan}

Pada penelitian ini telah diperlihatkan bahwa model penyebaran aflatoksin pada manusia dan hewan memiliki empat titik kesetimbangan, yaitu $E_{0}, E_{1}, E_{2}$, dan $E_{3}$. Terdapat dua angka reproduksi dasar, yaitu $R_{01}$ dan $R_{02}$, yang menentukan syarat eksistensi dan syarat kestabilan titik kesetimbangan. Titik kesetimbangan $E_{1}, E_{2}$, dan $E_{3}$ eksis dengan syarat tertentu. Titik kesetimbangan $E_{0}, E_{1}$, dan $E_{2}$ stabil asimtotik lokal dengan syarat tertentu, sedangkan titik kesetimbangan $E_{3}$ selalu stabil asimtotik lokal. Jika $R_{02}<1$ dan $R_{01}<1$ maka kandungan aflatoksin pada manusia dan hewan pada akhirnya akan habis, dan hanya terdapat aflatoksin 


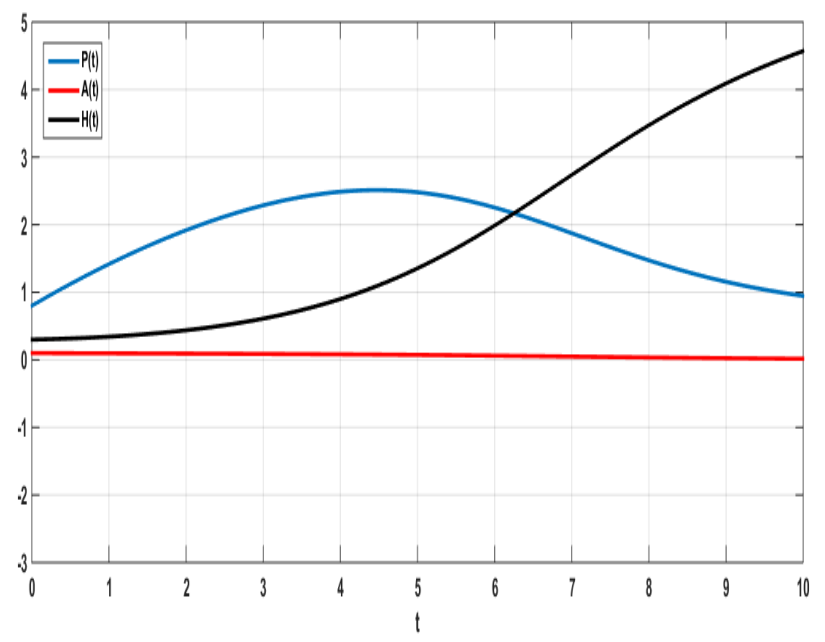

GAmBAR 7. Kurva solusi untuk kasus $R_{01}>1, R_{02}>1, T<R 01<R_{02}$. $A(t)$ tidak pernah bernilai negatif

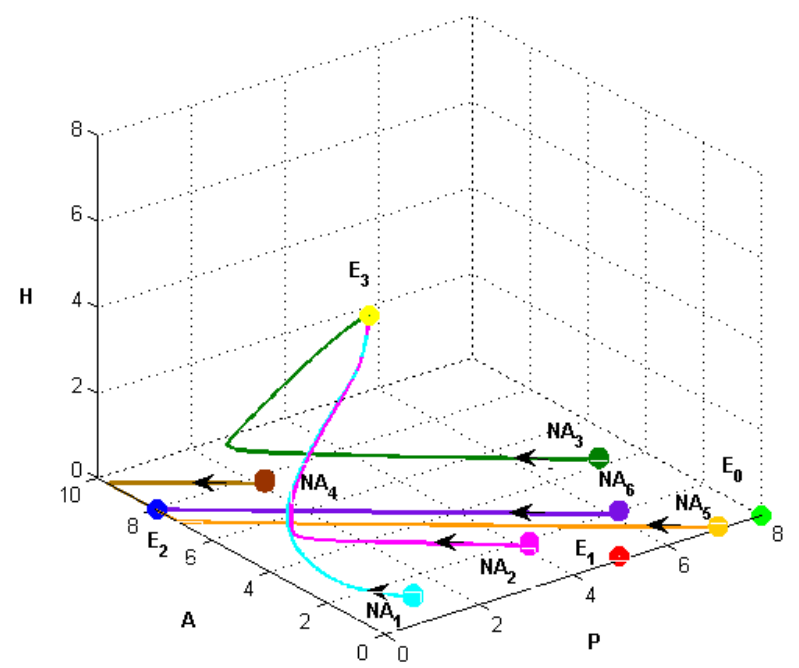

GAmbar 8. Potret fase untuk kasus $R_{02}>1, R_{01}>1$, dan $R_{02}<T<R_{01}$. Titik $E_{2}$ dan $E_{3}$ stabil asimtotik lokal

pada tanaman, sebab hanya titik kesetimbangan $E_{0}$ yang eksis dan bersifat stabil asimtotik lokal. Kondisi inilah yang diinginkan terjadi dalam situasi nyata, yaitu ketika tidak terdapat kandungan aflatoksin pada hewan dan manusia. Ketidakstabilan titik $E_{0}$ mengakibatkan titik kesetimbangan $E_{1}$ atau $E_{2}$ eksis. Jika $R_{02}=R_{01}$ maka titik $E_{3}=E_{0}$. Jika $R_{02}<R_{01}$ maka titik $E_{2}$ bersifat stabil asimtotik lokal. Sebaliknya, jika $R_{02}>R_{01}$ maka titik $E_{1}$ bersifat stabil asimtotik lokal. Simulasi numerik yang dilakukan menunjukkan hasil yang sesuai dengan hasil analisis. Berdasarkan hasil analisis pada model ini, dapat diusulkan kepada pihak-pihak pengambil kebijakan agar parameter-parameter dalam model ini menghasilkan nilai angka reproduksi dasar yang kecil. Seandainya angka reproduksi dasar tidak dapat ditekan, masih bisa diupayakan agar kandungan aflatoksin pada tumbuhan dan hewan tidak melebihi ambang 
batas, sebab kandungan aflatoksin berkantung pada parameter-parameter yang terdapat pada titik-titik kesetimbangan $E_{1}, E_{2}$, dan $E_{3}$.

\section{DAFTAR Pustaka}

[1] Astawan, M., 2009. Sehat dengan Hidangan Kacang dan Biji-Bijian, Penebar Swadaya, Jakarta.

[2] Battilani, P., Leggieri, M.C., Rossi, V., dan Giorni, P., 2013, AFLA-maize, a mechanistic model for Aspergillus flavus infection and aflatoxin B1 contamination in maize. Computers and Electronics in Agriculture, Volume 94, Hal. 38-46.

[3] Kademi, H.I., Baba, I.A., dan Saad, F.T., 2017, Modelling the dynamics of toxicity associated with aflatoxins in foods and feeds, Toxicology Reports, Volume 4, Hal. 358-363.

[4] Kademi, H. I., Saad, F. T., Ulusoy, B. H., Baba, I.A., dan Hecer, C., 2019, Mathematical model for aflatoxins risk mitigation in food, Journal of Food Engineering, Volume 263, Hal. 2529.

[5] Kifer, D., Jakšić D., dan Klarić, M. S., 2020, Assessing the effect of mycotoxin combinations: which mathematical model is (the most) appropriate?, Toxins, Volume 12, Hal. 153-173;

[6] Marin, S., Ramos, A.J., dan Sanchis, V., 2010, Modelling Aspergillus flavus growth and aflatoxins production in Pistachio nuts. Food Microbiology, Volume 32, Hal. 378-388

[7] Molina, M. dan Giannuzzi, L., 2002, Modelling of aflatoxin production by Aspergillus parasiticus in a solid medium at different temperatures, $\mathrm{pH}$ and propionic acid concentrations. Food Research International, Volume 35, hal.:585-594.

[8] European Commission, 466/2001/EC (2001) and 257/2002/EC (2002). Commission Regulation (EC) No 472/2002 of 12 March 2002 amending Regulation (EC) No 466/2001 setting maximum levels for certain contaminants in foodstuffs. Off. J. Eur. Union, 1820, L 075. 
52 Kusumawinahyu dkk, JMI Vol 16(1) April 2020 pp. 41-yy,doi:10.24198/jmi.v16.n1.27492.41-51 